\title{
STRESS IN COMPOUNDS: AN EXPERIMENTAL RESEARCH
}

\author{
PAVOL ŠTEKAUER - JÚLIUS ZIMMERMANN - RENÁTA GREGOVÁ \\ Department of British and \\ American Studies \\ Šafárik University \\ Moyzesova 50 \\ 04001 Košice \\ Slovakia \\ stekauer@condornet.sk \\ Institute of Slovak Stud- \\ ies, General Linguistics \\ and Mass Media Studies \\ Prešov University \\ Ul. 17. Novembra 1 \\ 08001 Prešov \\ Slovakia \\ zimmer@unipo.sk \\ Institute of British and \\ American Studies \\ Prešov University \\ Ul. 17. Novembra 1 \\ 08001 Prešov \\ Slovakia \\ r.gregova@yahoo.co.uk
}

Abstract: The paper deals with the role of stress in distinguishing between compounds and phrases. An experimental laboratory research aims (a) to examine the nature of stress in $\mathrm{N}+\mathrm{N}$ constructions in terms of its relative value, i.e., in relation to the values measured in neighbouring syllables; (b) to compare precise laboratory data with expectations of native speakers; (c) to compare precise laboratory measurement data with those obtained from native speakers who listened to a recording read by native speakers, in order to find out whether human ear perception corresponds to the results produced by computer technology; (d) to compare the laboratory data with the structural predictions using Giegerich's criteria (2004); (e) to compare the laboratory data with the semantic predictions based on Olsen (2000). The laboratory data are analyzed and commented on with regard to the individual research tasks and objectives specified in points (a) to (e) above.

Keywords: stress, compounds, phrases, English, experimental research

\section{Introduction}

The problem of the definition of English compounds and of drawing a clear-cut line between compounds as signs and phrases as syntactic units is one of a number of hard nuts in English word-formation that have not been satisfactorily cracked yet. While a number of criteria have been proposed to define compounds, the picture that emerges is that "none of the possible criteria gives a reliable distinction between two types of construction. The implication is that any distinction drawn on the basis 
of just one of these criteria is simply a random division of noun + noun constructions, not a strongly motivated borderline between syntax and the lexicon" (Bauer 1998, 78).

\section{Stress as a criterion of compoundhood}

In this article we will discuss and experimentally verify one of the most frequently adduced criteria, that of stress. To narrow down the scope of research, we will focus on the most characteristic and most productive group of English compounds, notably noun + noun compounds.

Stress can hardly be omitted in any serious discussion of compoundhood. This topic has been extensively discussed by both theoretical morphologists and phonologists.

Marchand (1960) maintains that a construction must meet the following condition to be classified as compound: "the compound must be morphologically isolated from a parallel syntactic group [...] Bláckbird has the morphophonemic stress pattern of a compound, bláck márket has not, despite its phrasal meaning; the latter therefore is a syntactic group [...] Stress is a criterion here" (op.cit., 14-5). From this it follows that the criterion is a single main stress (forestress) on the left-hand constituent. Unfortunately, there are many exceptions to this rule, and Marchand is aware of their existence. There are, for example, compounds that are double-stressed almost systematically, mainly those compounds whose second constituent is a participle (easy-going, high-born, man-made).

Bauer discusses this issue in great detail on a number of occasions, especially in $(1978 ; 1983 ; 1998)$, and agrees that "[t] here is a compound stress pattern in English [...], with a heavy stress on the first element [...]" (Bauer 1978, 37). However, while being aware of Marchand's approach mentioned above as well as Lees' $(1960,120)$ distinction between $\mathrm{N}+\mathrm{N}$ compounds and nominal phrases (depending on whether a structure contains one or two main stresses, respectively), and a number of other authors assigning the major stress to the left-hand constituent of a compound and to the right-hand constituent of a syntactic construction, Bauer takes a rather sceptical position because the "stress criterion is inconsistent" $(1978,89)$. Consequently, he concludes that "it makes more sense to talk of single and double stressed compounds than of compounds as opposed to noun + noun syntactic phrases" $(1983,109)$.

Inconsistency and vacillation in stress identification can be observed, as also suggested by Pennanen (1980), in individual native speakers, 
groups of speakers, and even various dictionaries (Bauer 1998, 70-2). The inconsistency is aggravated by differences across accents, the fact that in American English, "there is a stronger tendency towards the simplestressing of compounds" (Kingdon 1966, 164). It is for these reasons that Chomsky and Halle's compound rule (1968) cannot be accepted as a general rule of stress assignment in $\mathrm{N}+\mathrm{N}$ combinations.

Jones $(1969,258)$ presents three criteria conditioning the presence of a single main stress (on the left-hand constituent):

(i) The compound denotes a single new idea rather than the combination of two ideas suggested by the original words, i.e., the meaning of the compound is not a pure sum total of the meanings of its constituents.

(ii) The meaning of the compound noun is the meaning of the second constituent restricted in some important way by the first element ('birthday, 'cart-horse, 'sheepdog).

(iii) The first element is either expressly or by implication contrasted with something ('flute-player)

Bauer $(1983,107)$ aptly calls the last criterion - also mentioned, for example, by Marchand $(1960,16-7)$ and Kingdon $(1958,151)$ - in question by demonstrating that if this were the case, all compounds might be expected to be pronounced with forestress. For example, 'globe 'artichoke would require forestress only because it contrasts with 'Jerusalem 'artichoke; 'cherry 'brandy is contrasted with 'apricot 'brandy, 'peach 'brandy and 'grape 'brandy, although it is double stressed.

When the second compound constituent is felt to be especially important Jones $(1969,259)$ applies double stress. Examples include 'gas'stove (the importance of the second constituent follows from its contrast with fire in gas-fire - the traditional method of heating in England), 'eye-'witness, 'arm-'chair, 'bow-'window.

Jones also discusses compounds with three constituents. They usually have single stress on the second constituent if the first two constituents taken alone form a double stressed compound, for example, ginger-'beer-bottle and waste-'paper-basket. Otherwise, three constituent compounds have primary stress on the first constituent, for example, 'teapothandle, 'teaspoonful, 'sodawaterbottle (op.cit., 261).

Much of the relevant literature discusses the role of meaning in placing the stress in $\mathrm{N}+\mathrm{N}$ compounds/phrases. It should be, however, noted that any attempts to find systematic correlations between stress and the 
meaning of the head noun of $\mathrm{N}+\mathrm{N}$ constructions (such as Lees' (1960) lexical conditioning of stress) appear to be restricted to minor lexical groups, and can hardly be generalized into hard-and-fast rules. Thus, for example, Sampson (1980, 265-6) identifies the 'made of' relation as one requiring secondary stress on the left-hand constituent and primary stress on the right-hand constituent as a general rule (iron sáucepan, plàstic búcket, rùbber bánd). However, this general rule needs further refinement. First, the object named must be an artefact. For this reason, the stress pattern in expressions like sánd dùne and wine stàin is reversed. Second, the object named must be an artefact of a fixed form. Hence, $\mathrm{N}+\mathrm{N}$ combinations with the first constituent referring to a liquid have the 'primary stress-secondary stress' pattern, as in wáter dròplet and óil slick. But, this is not the end of the story. Sampson gives a number of exceptions to the 'fixed made-of artefact' stress rule. Moreover, as noted by Spencer $(2003,7)$, "individual words which regularly feature in compounds (especially heads) can create their own islands of systematicity, sometimes in opposition to a prevailing trend for words of the same semantic field". This, in fact, corresponds to Sampson's observations of new diachronic trends consisting in switching the primary stress "away from the first $\mathrm{N}$, where this otherwise would be considered normal, and onto the second N" (Sampson 1980, 267-8). This emerging trend seems to be subject to certain constraints:

(i) lexical - the new pattern mainly occurs if the second constituent refers to an organisation, official body, and appointment;

(ii) syntactic - the new pattern mainly occurs if the respective NP is placed at the end of a sentence;

(iii) sociolinguistic

a. speakers - 'mass communicators' in radio and TV broadcasting, politicians, etc.

b. situations - reading aloud a prepared written text.

Both phonologists and morphologists, for example, Kingdon (1958, 147), Roach $(1983,100)$, and Bauer $(1983,103)$ point out a related problem: the position of stress in isolation may differ from that when such words are pronounced in sentence context, and some others (Spencer 2003, 6-7) note that stress can occasionally be used to distinguish between different readings of the same combination of constituents, for example 'toy factory is probably a factory where toys are made, but a toy 'factory is a factory 
which is also a toy, along with all sorts of other toys, like toy gun, toy boat, and so on.

One of the most recent attempts to come to grips with the problem of compoundhood by employing the stress criterion is Giegerich (2004). He agrees with Liberman and Sproat (1992) who distinguish between end-stressed $\mathrm{N}^{1}$ categories (phrases) and forestressed $\mathrm{N}^{0}$ categories (compounds). Giegerich justifies this distinction by relating stress to the structural characteristics of $\mathrm{N}+\mathrm{N}$ constructions. Attribute-head $\mathrm{N}+\mathrm{N}$ constructions are, in his view, phrasal, and therefore have end stress (stress on the right-hand constituent). From the semantic point of view, they are characterized by the relation 'made of' or, more generally, 'associated with' (the steel bridge type). Since the attributive function is typically realised by an adjective, this type of $\mathrm{N}+\mathrm{N}$ combinations can be paraphrased with real or imaginary adjectives (horse shoe: equine shoe, post office: postal office, bread roll:breaden roll). On the other hand, forestressed $\mathrm{N}+\mathrm{N}$ combinations are complement-head structures that are lexicalised (importantly, lexicalization is a diachronic process that can feature individual differences) (e.g., battlefield, fruit-market, handcream - these are characterized by the semantic relation $\mathrm{N}_{2}$ for $\mathrm{N}_{1}$ ).

Giegerich is also aware of many non-systematic deviations from the scheme outlined above. He necessarily arrives at the same conclusion as Spencer who puts it pregnantly: "[...] we find compounds with Compound Stress and Phrasal Stress, and we find phrases with Phrasal Stress and Compound Stress. That is, there is a double dissociation between stress and structure" (op.cit., 4-5). Therefore, instead of the effort to identify two clearly separated groups of constructions (compounds vs. phrases), he speaks of "substantial overlap, with a cline between the extremes of attribute-head NNs such as steel bridge at the syntax end and deeply lexicalised silverfish" (ibid.:8).

While Giegerich's discussion is highly interesting and elaborate, he himself admits that his theory does not solve the problem of compound definition and that the constructions falling within $\mathrm{N}^{0}$ (compound) are rather heterogeneous. Certainly, with regard to the steel bridge type of $\mathrm{N}+\mathrm{N}$ constructions, one may argue, that lexicalisation is too vague a criterion for stress assignment, and given the above-mentioned fact that it may differ from speaker to speaker of a language, it can hardly be taken as a reliable indicator of stress placement. In other words, changes in stress would be due to the unpredictable process of lexicalisation. As a result, there is no space for a systematic word-formation process. It is not 
clear why (at least some part of) compounds should be, unlike prefixation, suffixation, conversion, blending, and back-formation, an outlaw that is not allowed to be used for a direct naming process. Instead, to put it figuratively, the fate of syntactic $\mathrm{N}+\mathrm{N}$ phrases is put in the hands of the overpowerful process of lexicalisation.

On top of it, Plag (2006) concludes that since lexicalisation correlates with frequency "we should find more modifier-head structures with leftward stress among the more frequent items. And we should never find rightward stress among those NN constructs that exhibit complementhead order" (op.cit., 146). However, as indicated above, the latter point is not always true. Moreover, Plag's data indicate "that modifier-head compounds show variably rightward and leftward stress and that this variability [...] cannot be explained as a lexicalization effect" (ibid.: 166).

Last but not least, let us mention an approach proposed by Ladd (1984). Ladd not only describes facts but also provides a highly interesting explanation of the application of a compound stress pattern. In his view, compound stress is marked - unlike phrasal stress. "[C]ompound stress represents the deaccenting of the head of the compound" (op.cit., 257 ) and should be examined in sentence context as it makes "some independent semantic/pragmatic contribution to the interpretation of the sentence [...]" (ibid.:258). Ladd makes Dowty's (1979) concept of 'appropriately classificatory relation', ${ }^{1}$ implying a new subcategorization of the head noun, a condition for the application of compound stress. For illustration, in green house, the head noun house is not newly subcategorized; it is just described in terms of colour. On the other hand, the deaccentation of house in greenhouse signals a new subcategorization of the head noun. This accounts, inter alia, for the above-mentioned trend to apply phrasal stress to the 'made of' $\mathrm{N}+\mathrm{N}$ units: steel wárehouse ('a warehouse made of steel') as opposed to stéel warehouse ('warehouse for storing steel'). The compound stress in the latter case indicates that "warehouse is indeed being classified into some subcategory by steel, and [...] B for storing $A$ is a reasonable classificatory relation to infer between those two nouns" (Ladd 1984, 264). Thus, the crucial factor conditioning stress assignment is in Ladd's view "whether the attribute categorizes or merely describes the head" (op.cit., 165).

${ }^{1}$ It should be noted that the first to use this term was Zimmer (1971).

Acta Linguistica Hungarica 54, 2007 


\section{Former experimental studies}

The works mentioned in the previous section as well as the vast majority of other articles discuss the stress pattern of $\mathrm{N}+\mathrm{N}$ combinations from a theoretical (intuitive) point of view. There have been only few research projects based on laboratory experiments.

Farnetani, Torsello and Cosi (Farnetani et al. 1988) analyse the prosodic pattern distinguishing compounds and parallel non-compound noun phrases and evaluate how an information structure (presented as either new or old information) and different sentence positions influence the production and perception of these compounds and parallel phrases.

The experimental sample included compound and phrase forms of Italian teacher, paper bag and working woman occurring in constructed stretches of discourse in order to present these pairs in meaningful contexts resembling spontaneous speech. The research was aimed at functional, acoustic and perceptual analyses. The functional analysis included the analysis of the linguistic context in terms of old and new information. In the acoustic analysis pitch ( $\mathrm{F}_{0}$, i.e., fundamental frequency), duration of the analysed constructions as a whole, and intensity peaks within the lexically stressed syllables of tested words were measured and analysed. In the perceptual part of the research, five listeners were asked to identify what they hear (whether compound or a phrase) and to indicate the degree of confidence in identification. Finally, the relations between the acoustic parameters measured and the listeners' responses were compared.

The data obtained from both production and perception analyses showed that the distinction between compounds and phrases is based on difference in prominence pattern (compounds are created by an accented + an unaccented element and phrases have the structure accented + accented constituent) and in temporal cohesion (phrases are longer than compounds). In both forms, the constituent containing information which is not new, i.e., information accessible from the context, is deaccented.

The most recent experiment is Plag (2006). An experimental research is used by Plag to evaluate the validity of three different hypotheses on stress assignment to NN combinations, in particular, the structural hypothesis (compounds are left-stressed); the semantic hypothesis (right-hand stress is restricted to a limited number of well-defined semantic relationships, such as temporal (summer night), locative (Boston 
márathon), 'made of' (aluminium fóil), 'created by' (Shakespeare sónnet), etc.); and the analogy hypothesis (stress assignment is governed by analogy to existing NN combinations in the mental lexicon: all street names, for example, with street as the right-hand member are left-stressed while all avenue-based NN combinations are right-stressed). It is precisely the examination of possible correlations between the precise laboratory data and the individual stress-assignment hypotheses that appears to be the most important contribution of Plag's research. Importantly, his experimental research demonstrates (a) considerable variability in NN stress; (b) all three stress assignment principles play their role in stress assignment in English NN combinations.

In any case, the methodology of Plag's research raises some doubts. Plag measured the pitch as "the most important acoustically measurable correlate of stress" (Plag 2006, 150). He measured the fundamental frequency in the middle of the main stressed vowels of the two compound members. Thus, for example, when both elements of opera glasses are used in isolation, it is supposed that the main stress is on o in opera (ópera) and on $a$ in glasses (glásses). The point is that this method partly anticipates the possible place of the main stress, and disregards some other options, which actually should be the aim of this kind of research. The level of stress on individual syllables, i.e., the position of the main stress, can be different when the words are elements of a compound, and even different when the compound is in context. In our view, the problem of stress assignment in compounds and phrases requires an 'unprejudiced' approach, i.e., it is necessary to analyse a given construction as a whole, without any anticipation of the position of stress. We find it important to analyse acoustic correlates of stress in every syllable of a given construction. Then, the statistical processing and evaluation of data makes it possible to identify the main-stress vowel.

All in all, the question is to what degree the 'reduced-scope' method used by Plag may have influenced the data obtained and analysed.

\section{Experiment}

Given this discouraging picture, a number of questions emerge:

- Are there two different groups of $\mathrm{N}+\mathrm{N}$ constructions, one of them being compounds and the other syntactic phrases? 
- If there are, what is the role of stress in defining the two groups? Are all lefthand-stressed $\mathrm{N}+\mathrm{N}$ units compounds and all righthandstressed ones phrases?

- Is there any justification for considering righthand-stressed constructions of this sort morphological compounds?

- If there is, what is the reason for the different stress patterns?

- What is the role of semantic relations between the $\mathrm{N}+\mathrm{N}$ construction constituents in defining the two groups?

- What is the role of structural relations between the $\mathrm{N}+\mathrm{N}$ construction constituents in defining the two groups?

- What is the role of context in placing the stress?

- Are there any differences between stress expectations of native speakers vs. experts, and stress identification by native speakers in view of these expectations?

- Are there any differences between the results obtained by means of precise laboratory methods and by means of "listening" experiments?, etc.

The primary purpose of our research was to verify the intuitive claims concerning the position of stress in compounds as presented in the theoretical literature by means of measurements using highly precise, advanced laboratory instruments. In particular, our research aimed to:

(i) examine the nature of stress in isolated and contextual $\mathrm{N}+\mathrm{N}$ constructions;

(ii) compare exact laboratory data with expectations of experts (semantic and structural criteria);

(iii) compare exact laboratory measurement data with those obtained from native speakers who listened to a recording read by native speakers, with the aim to find out whether human ear perception corresponds to the results produced by computer technology.

\subsection{Method}

An accidentally selected newspaper text was read by two native English speakers, both of them males with an academic background. The preference for males lies in better natural characteristics of man's voice. The informants participated in the experiment independently of each other, without any mutual co-operation. In the experiment itself, a native speaker was given a printout with a text (see Appendix A) on one 
side, and with thirty-one isolated $\mathrm{N}+\mathrm{N}$ constructions extracted from the original text (see Appendix B). ${ }^{2}$

A personal computer was equipped with signal processor, microphone, speakers, and the Multi-Speech software. It is a program designed for a comprehensive phonetic analysis of the acoustic speech signal. An output of the analysis includes the time behaviour of the basic tone and intensity changes, the sonant nucleus duration, etc. Since the program always analyzes a digitized signal, it applies discrete mathematical methods to the calculation of the aforementioned speech characteristics.

\subsection{Procedure}

The experiment was aimed at the analysis of stress. The following algorithm was used:

(i) Signal digitization.

(ii) Identification and segmentation of the sonantic nucleus of each syllable.

(iii) Computation of an effective value of the sonantic nucleus RMS signal, that is to say, the computation of the sonantic nucleus intensity. This value is represented as an effective signal value calculated as a root mean square (RMS).

(iv) Computation of an average value of the sonantic nucleus basic tone.

The core of the experiment was an analysis of the intensity and the basic tone of sonantic nuclei of all syllables. ${ }^{3}$ Since discrete mathematical methods were applied, the speech signal was segmented to $5 \mathrm{~ms}$ time frames. In diphthongs and long vowels, a $50 \mathrm{~ms}$ dominant frame was analysed. The data for the individual informants were compared, and the relevant findings were statistically processed.

${ }^{2}$ When pronouncing the analysed $\mathrm{N}+\mathrm{N}$ constructions in isolation, the speakers were instructed to adhere to the monotonous tone of speech in order to avoid the properties of the falling tone. Since in the case of the falling tone-typical of final statements - all three parameters of the syllabic nuclei (intensity, pitch, length) primarily generate the end of the sentence (utterance) and the observed phenomenon is only secondary and experimentally immeasurable.

3 The main functions of quantity (the length or duration of a syllabic nucleus) are: (1) to create long vowels; (2) to create diphthongs; (3) to participate in the creation of stress. In our material, there were only a few cases in which quantity had to fulfil function (3), that is why we had to exclude this phenomenon from our measurements.

Acta Linguistica Hungarica 54, 2007 
The results concerning the position of stress in the analysed $\mathrm{N}+\mathrm{N}$ constructions produced by computer technology were compared to the results of a perceptual test.

46 native speaker informants (university undergraduates) listened to the recordings of both isolated $\mathrm{N}+\mathrm{N}$ constructions as well as the text including these constructions. The students were provided with a printed copy, including both the list of separate $\mathrm{N}+\mathrm{N}$ constructions and the text. In the textual version, the relevant $\mathrm{N}+\mathrm{N}$ constructions were printed in bold so that the informants could concentrate on the identification of the main stress positions in these constructions. The data obtained were statistically processed and evaluated.

The core of the experiment was an analysis of the intensity and the basic tone of sonantic nuclei of all syllables, since a research into stress requires an analysis of its physical (acoustic) correlates, in particular, intensity and fundamental frequency (pitch). It should be noted that stress is a relative property of two neighbouring syllables. From this it follows that only by comparing the relative values of intensity and pitch can we determine which of them is more stressed. Stress is a continuous rather than discrete feature of a syllable. Syllables cannot be divided into stressed and unstressed in absolute values, because intensity and pitch are analogue parameters. It is only the probability of stress that can be determined. Listeners unanimously identify syllables as stressed or unstressed in terms of dominant values of intensity and pitch in contrast to their environment.

Given this complicated background of research into N + N stress patterns, it is proposed in our approach to make use of the visualisation of the oscillation of statistically processed values of the fundamental frequency and intensity of syllables and the perceptually determined probability of stress patterns. ${ }^{4}$

The analysed constructions were divided into four categories:

(i) disyllabic compounds pronounced in isolation

(ii) disyllabic compounds pronounced in context

(iii) polysyllabic compounds pronounced in isolation

(iv) polysyllabic compounds pronounced in context.

${ }^{4}$ Oscillation means the variance of the measured values of the fundamental tone and intensity of sonantic nuclei. Both measured values and stress perception differ in each consecutive realisation of the sample constructions. Statistical evaluation makes it possible to cope with value oscillations. 
The reason for this division is the alternation of stressed and unstressed syllables in the analysed material; according to the perceptual tests, it is probable that both syllables in the disyllabic compounds are stressed; on the other hand, polysyllabic constructions can be modelled by the sequence U S U U S U U S U U (U-unstressed syllable, S-stressed syllable). This stress sequence is based on the perceptually identified stress probability (see Table 1).

Table 1

Representation of polysyllabic constructions as the USUUSUUSUU sequence

\begin{tabular}{|c|c|c|c|c|c|c|c|c|c|c|}
\hline & $\bar{U}$ & $\mathrm{~S}$ & $\mathrm{U}$ & $\mathrm{U}$ & S & $\bar{U}$ & $\bar{U}$ & $\bar{S}$ & $\bar{U}$ & $\mathrm{U}$ \\
\hline wintə əชlımpıks & & win & tə & $\partial v$ & $\lim$ & pIks & & & & \\
\hline (sə:lt lerk) siti rezidənts & & SI & ti & & re & $\mathrm{zi}$ & dənts & & & \\
\hline sıkjvərəti ri:zənz & SI & kjwə & rə & $\mathrm{ti}$ & ri: & zənz & & & & \\
\hline bro:dka:st raits & & bro:d & ka:st & & raits & & & & & \\
\hline tenis $\int u:$ & & te & nis & & fu: & & & & & \\
\hline to:t beərəz & & to:t & & & beə & rəz & & & & \\
\hline hpki ti:m & & $\mathrm{hp}$ & ki & & ti:m & & & & & \\
\hline proksi wo: & & pro & ksi & & wว: & & & & & \\
\hline brarbəri germz & & braI & bə & ri & germz & & & & & \\
\hline miljən dolə bu:ti & & $\mathrm{mI}$ & ljən & & $\mathrm{dp}$ & lə & & bu: & ti & \\
\hline (so:lt leik) əfiflz & ә & $\mathrm{fI}_{\mathrm{I}}$ & $\int l z$ & & & & & & & \\
\hline braıbəri fa:dgız & & braI & bə & ri & tfa: & diz & & & & \\
\hline sIkjひərəti naItmeə & SI & kjøə & rə & $\mathrm{ti}$ & nait & meə & & & & \\
\hline әvlımpık pa:k bomı & $\partial \mho$ & $\lim$ & prk & & pa:k & & & bo & mig & \\
\hline lə: infə:smənt eIdzənsiz & & lo: & In & & fo:s & mənt & & eI & dən & $\operatorname{siz}$ \\
\hline әtlæntə bsdgit & ә & tlæn & tə & & $\mathrm{b} \Lambda$ & dgit & & & & \\
\hline metəl ditektə & & me & təl & dI & tek & tə & & & & \\
\hline snəひməbi:lz & & snəひ & & & mə & bi:lz & & & & \\
\hline həumlænd sıkjvərəti (tgiff) & & həชm & & & lænd & SI & & kjøə & rə & ti \\
\hline həひst kıntri kəひd & & həvst & & & $\mathrm{k} \Lambda \mathrm{n}$ & tri & & kəvd & & \\
\hline pætriət germz & & pæ & tri & at & geımz & & & & & \\
\hline
\end{tabular}

Each subgroup is represented by a specific diagram (Figures 1-4) with each syllable identified by its respective number on the horizontal axis; the left-hand vertical axis represents pitch, the right-hand vertical axis represents intensity and the perceptual probability of stress. The scales of both axes make it possible to perceive any visually observable decrease 
or increase of the parameter value also at the acoustic level (it should be emphasized that the perceptual boundaries are not clear-cut; on the contrary, they feature substantial dispersion). The diagrams identify the mean values of three parameters - pitch (marked by circles), intensity (marked by squares) and stress probability (marked by triangles) for each syllable as well as a $95 \%$ confidential interval for the mean value (with the maximum and minimum values at the end points of the axis).

\subsection{Results}

The following conclusions can be drawn from the diagrams (Figures 1-4).

Disyllabic constructions (Figures 1-2) behave differently in isolation and in context. In isolated pronunciation, the first syllable has a higher intensity and pitch than the second syllable, and a recipient perceives the first syllable more stressed than the second syllable. The dispersion of stress perception is lower in isolation than in context.

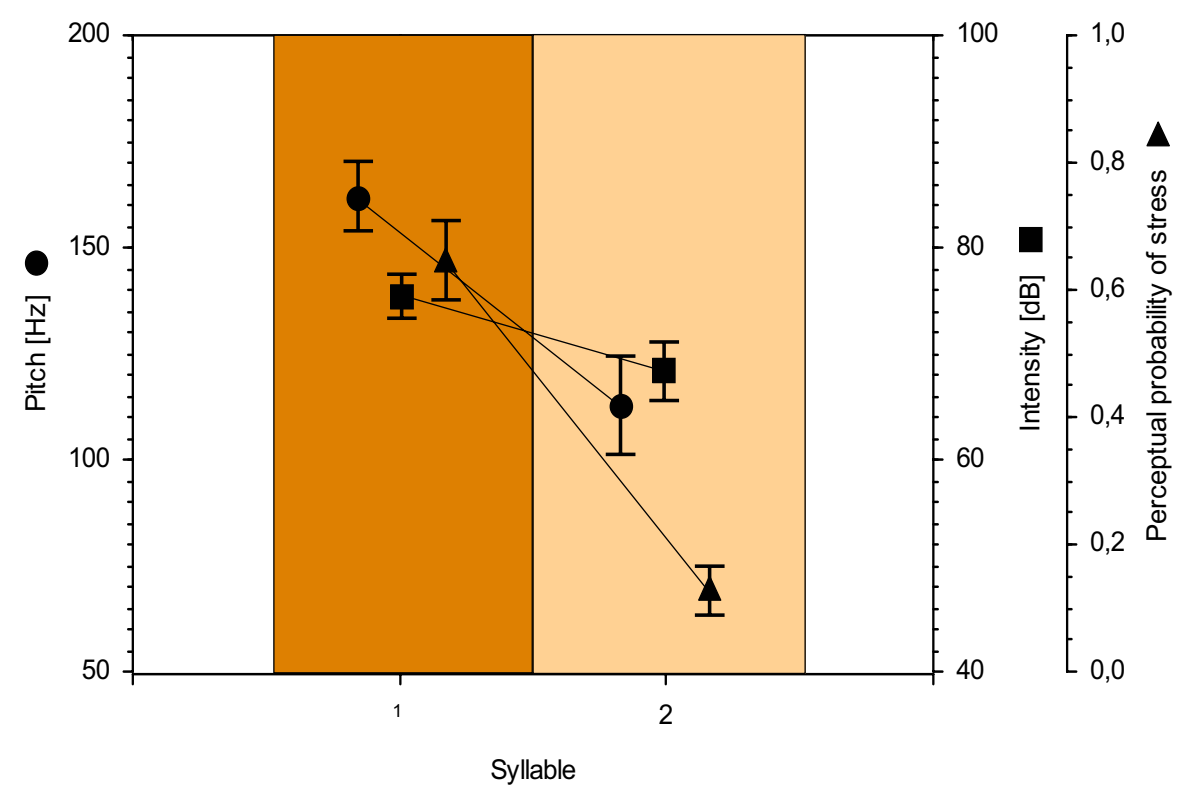

Fig. 1

Disyllabic constructions in context 


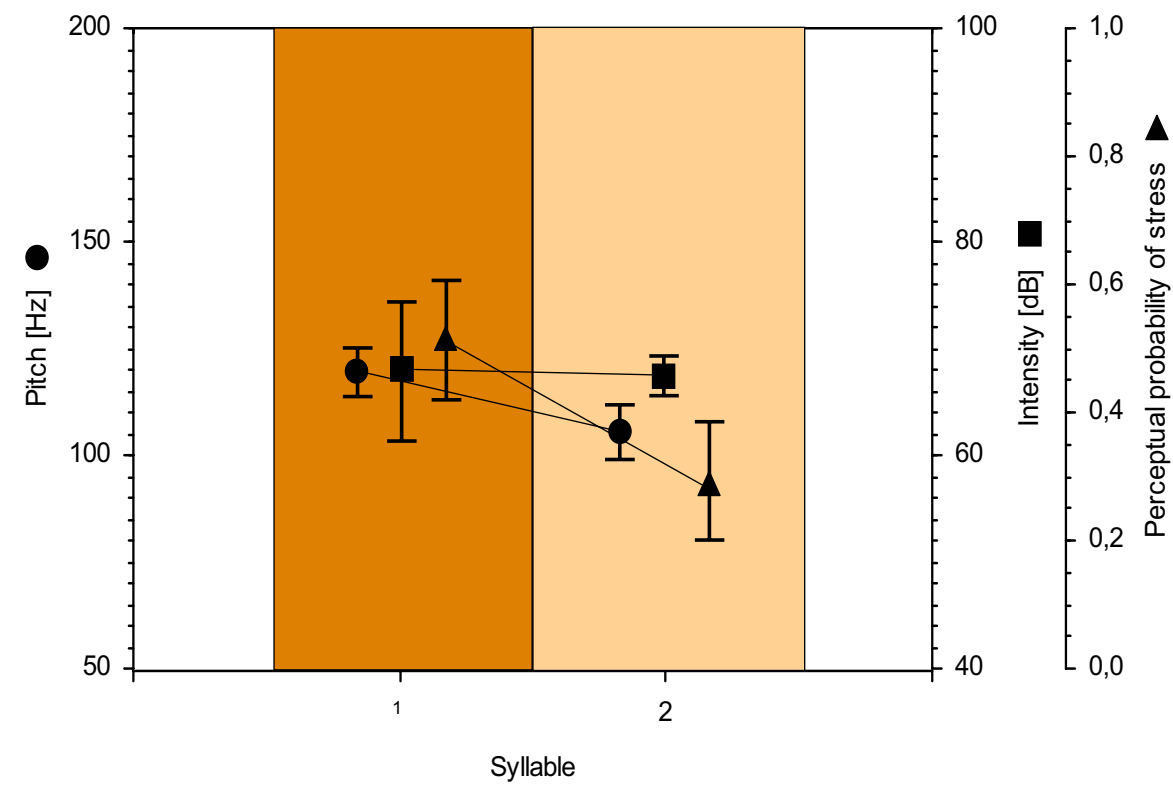

Fig. 2

Disyllabic constructions in context

In polysyllabic constructions (Figures 3-4), the model sequence U S U U S U U S U U is unambiguously captured by perception, and is very well mapped by pitch and intensity on the second syllable, not so well on the fifth syllable, and fairly well on the eighth syllable. Syllables in polysyllabic isolated constructions are more significantly stressed than those in contextual polysyllabic constructions. The correspondence between stress perception and intensity is better than that between stress perception and pitch. And finally, dispersion in the syllable parameters rises towards the end of the model sequence.

\subsection{Some comparisons}

\subsubsection{Isolated vs contextual $\mathbf{N}+\mathbf{N}$ constructions}

Laboratory measurements of isolated and contextual pronunciation of our sample expressions, summarised in Table 2, suggest that stress pattern differences between isolated and contextual pronunciation occur in seven cases for Speaker 1 and in eight cases for Speaker 2. Surprisingly, there are 


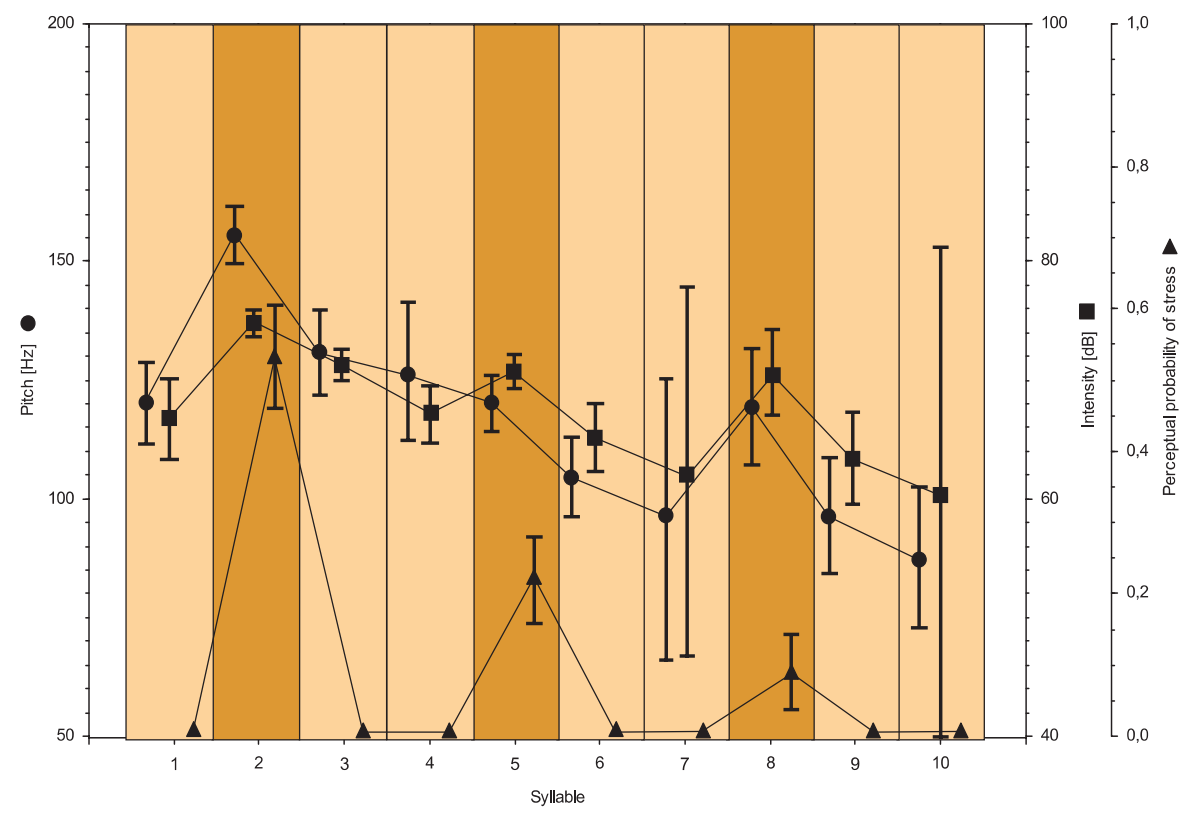

Fig. 3

Polysyllabic isolated constructions

only two cases (indicated by bold in Table 2), Winter Olympics and Salt Lake officials, which feature a different stress pattern for both speakers. But even in these instances, the two speakers differ in their respective contextual and isolated realisations.

An interesting observation pertains to dogsled, wheelchair, snowshoe, tennis shoe, tugboat. They are connected paratactically, in each case by the conjunction and. While there is full identity in assigning left stress (for both speakers) for dogsled, snowshoe, and tugboat, Speaker 1 realised wheelchair and tennis shoe differently not only from isolated pronunciation but also form the other instances in the paratactic relation. This is surprising mainly for tennis shoe as one would expect the pronunciation analogical to snowshoe.

The differences occur in all sentence positions - at the beginning, in the middle, and at the end. 


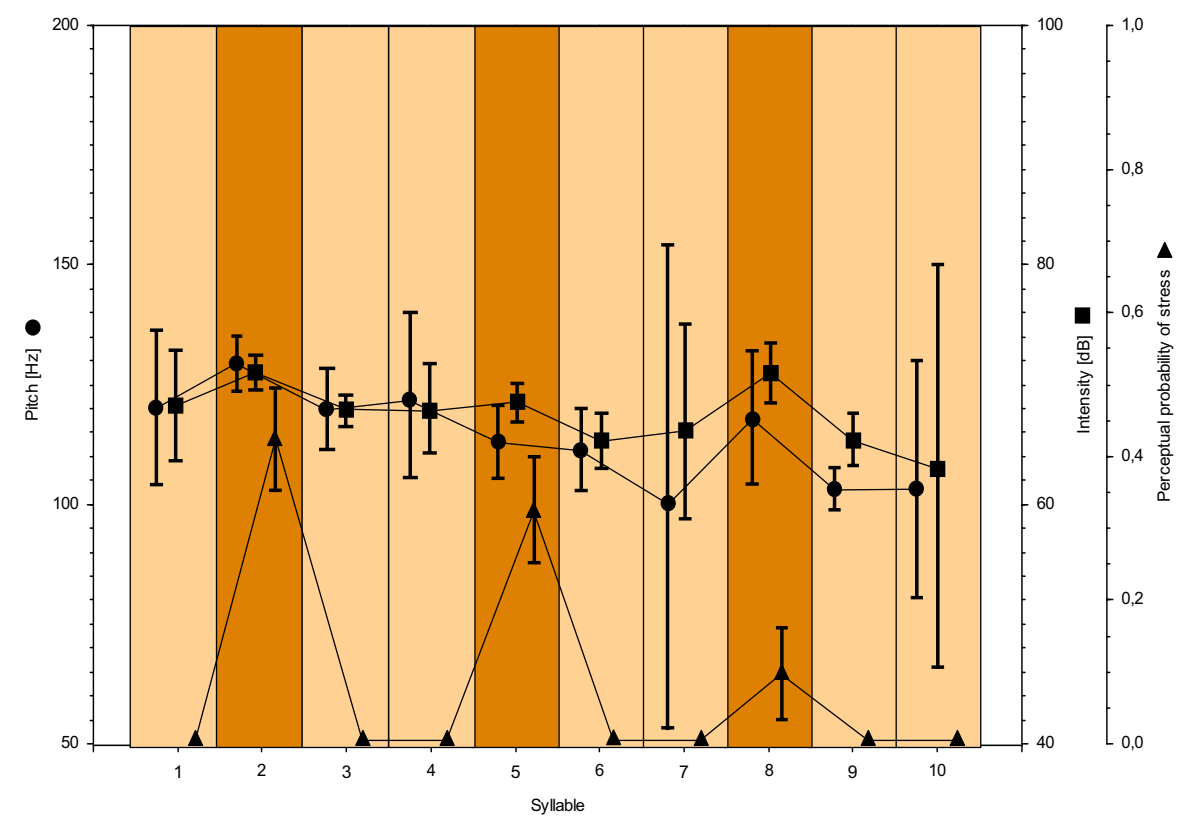

Fig. 4

Polysyllabic constructions in context

\subsubsection{Exact laboratory data vs. expectations of experts}

The expectations of experts were compared with the production of separate units as, obviously, expectations cannot predict the influence of context.

The measured data were compared to Giegerich's structural criterion. Giegerich distinguishes two types of $\mathrm{N}+\mathrm{N}$ structures, i.e., (a) modifier + head correspond to syntactic phrases and therefore feature a phrasal stress; (b) complement-head structures differ from syntactic structures because complements follow heads in syntax. They are therefore left-stressed. The existence of numerous left-stressed modifier-head structures is explained by their lexicalisation. As noted by Plag (2006), lexicalisation is connected with the frequency of occurrence. It may be added that lexicalisation is also subjectively conditioned, which makes this criterion rather problematic (as indicated by the results). In any case, we appreciate Giegerich's help who personally marked our sample expressions for stress. 
Table 2

Differences in contextual vs. isolated pronunciation

\begin{tabular}{lcccc}
\hline \hline $\begin{array}{l}\text { Isolated and contextual } \\
\text { pronunciation }\end{array}$ & \multicolumn{2}{c}{ Speaker 1} & \multicolumn{2}{c}{ Speaker 2} \\
Agreement & \multicolumn{2}{c}{24} & \multicolumn{2}{c}{23} \\
Differences & \multicolumn{2}{c}{7} & \multicolumn{2}{c}{8} \\
\hline & \multicolumn{2}{c}{ Speaker 1} & \multicolumn{2}{c}{ Speaker 2} \\
Expression & Context & Isolated & Context & Isolated \\
\cline { 2 - 5 } Winter Olympics & $\mathbf{R}$ & L & L & $\mathbf{R}$ \\
security reasons & $\mathrm{R}$ & $\mathrm{L}$ & $\mathrm{L}$ & $\mathrm{L}$ \\
wheelchair & $\mathrm{R}$ & $\mathrm{L}$ & $\mathrm{L}$ & $\mathrm{L}$ \\
tennis shoe & $\mathrm{D}$ & $\mathrm{L}$ & $\mathrm{L}$ & $\mathrm{L}$ \\
Salt Lake officials & L & $\mathbf{R}$ & $\mathbf{R}$ & $\mathbf{L}$ \\
security nightmare & $\mathrm{R}$ & $\mathrm{L}$ & $\mathrm{L}$ & $\mathrm{L}$ \\
metal detector & $\mathrm{R}$ & $\mathrm{L}$ & $\mathrm{L}$ & $\mathrm{L}$ \\
hockey team & $\mathrm{L}$ & $\mathrm{L}$ & $\mathrm{R}$ & $\mathrm{L}$ \\
proxy war & $\mathrm{D}$ & $\mathrm{D}$ & $\mathrm{D}$ & $\mathrm{L}$ \\
million dollar booty & $\mathrm{L}$ & $\mathrm{L}$ & $\mathrm{D}$ & $\mathrm{R}$ \\
bribery charge & $\mathrm{L}$ & $\mathrm{L}$ & $\mathrm{R}$ & $\mathrm{L}$ \\
snowmobiles & $\mathrm{L}$ & $\mathrm{L}$ & $\mathrm{L}$ & $\mathrm{D}$ \\
host-country code & $\mathrm{L}$ & $\mathrm{L}$ & $\mathrm{D}$ & $\mathrm{L}$ \\
\hline \hline
\end{tabular}

The semantic criterion (Olsen 2000) maintains that phrasal stress characterizes the semantic relations of MADE OF (if the object is an artefact), LOCATIVE and TEMPORAL relations, COPULATIVE COMPOUNDS, etc. The results are given in Table 3 .

The data show that in eight cases Speaker 1 realised the stress patterns differently from semantic expectations and in twelve cases differently from the structural expectations. The unambiguous tendency is to use a compound stress pattern instead of phrasal stress and/or level stress expectations following from the semantic and/or structural criteria. There is no case of phrasal realisation instead of compound expectation. Six out of seven differences pertain to the LOCATION relation.

${ }^{5}$ Legend for Tables 2-5: "R" - stress on the right-hand constituent; "L"—stress on the left-hand constituent; " $\mathrm{D}$ "—-level stress; Agreement/difference - the number of expressions for which there is agreement/difference between the compared parameters (in this case, isolated vs. contextual pronunciation). 
Table 3

Expectations vs. measurements

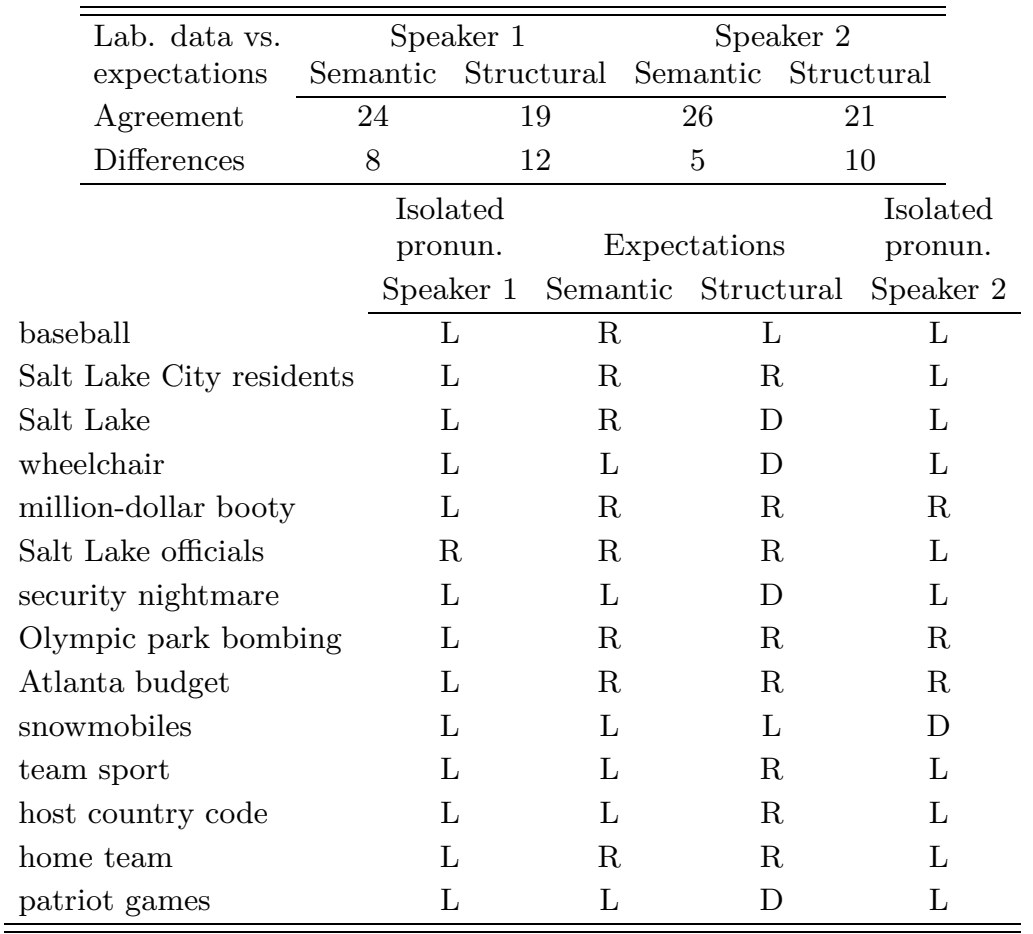

With Speaker 2, the respective number of differences is five and ten, respectively. Also here there is no case of replacing an expected compound stress by a phrasal stress.

As for the evaluation of theoretical predictions, the semantic criterion seems to be more reliable than that proposed by Giegerich. All in all, none of the criteria proposed provides us with a safe ground for the distinction between compounds and phrases.

\subsubsection{Measurements vs. perception}

\subsubsection{Production vs. perception: isolated units}

The data indicate that laboratory measurements do not significantly differ from our perception abilities. The mismatches feature the tendency of the left constituent stress for production and right constituent stress for perception (Table 4). 
Table 4

Production vs. perception: isolated units

\begin{tabular}{|c|c|c|c|c|}
\hline & \multicolumn{2}{|c|}{ Speaker 1} & \multicolumn{2}{|c|}{ Speaker 2} \\
\hline Agreement & \multicolumn{2}{|c|}{29} & \multicolumn{2}{|c|}{28} \\
\hline Differences & \multicolumn{2}{|c|}{2} & \multicolumn{2}{|c|}{3} \\
\hline \multirow{3}{*}{$\begin{array}{l}\text { Expression } \\
\text { security reasons }\end{array}$} & \multicolumn{2}{|c|}{ Speaker 1} & \multicolumn{2}{|c|}{ Speaker 2} \\
\hline & Measurement & Perception & Measurement & Perception \\
\hline & $\mathrm{L}$ & $\mathrm{R}$ & & \\
\hline Olympic bombing & $\mathrm{L}$ & $\mathrm{R}$ & & \\
\hline Salt Lake City residents & & & $\mathrm{L}$ & $\mathrm{R}$ \\
\hline security nightmare & & & $\mathrm{L}$ & $\mathrm{R}$ \\
\hline snowmobile & & & $\mathrm{D}$ & $\mathrm{L}$ \\
\hline
\end{tabular}

\subsubsection{Production vs. perception: contextual units}

The number of differences in context is much higher than that for separate units, which might indicate the negative (?) influence of context upon perception of language users. Interestingly, there is a strong tendency to perceive the measured compound stress as a phrasal stress (Table 5).

\section{Conclusions}

(i) The central finding of our research at the general level comes from section 4.3. Let us therefore reiterate it:

- Disyllabic constructions behave differently in isolation and in context. The dispersion of stress perception is lower in isolation than in context.

- In polysyllabic constructions, the model sequence U S U U S U U $\mathrm{S} \mathrm{U} \mathrm{U}$ is unambiguously captured by perception, and is very well mapped by pitch and intensity on the second syllable, not so well on the fifth syllable, and fairly well on the eighth syllable.

- Syllables in polysyllabic isolated constructions are more significantly stressed than those in contextual polysyllabic constructions.

- The correspondence between stress perception and intensity is better than that between stress perception and pitch.

- Dispersion in the syllable parameters rises towards the end of the model sequence. 
Table 5

Production vs. perception: contextual units

\begin{tabular}{|c|c|c|c|c|}
\hline & \multicolumn{2}{|c|}{ Speaker 1} & \multicolumn{2}{|c|}{ Speaker 2} \\
\hline Agreement & \multicolumn{2}{|c|}{21} & \multicolumn{2}{|c|}{24} \\
\hline Differences & \multicolumn{2}{|c|}{10} & \multicolumn{2}{|c|}{7} \\
\hline & \multicolumn{2}{|c|}{ Speaker 1} & \multicolumn{2}{|c|}{ Speaker 2} \\
\hline Expression & Measurement & Perception & Measurement & Perception \\
\hline Salt Lake City residents & $\mathrm{L}$ & $\mathrm{R}$ & & \\
\hline wheelchair & $\mathrm{R}$ & $\mathrm{L}$ & & \\
\hline tennis shoe & $\mathrm{D}$ & $\mathrm{L}$ & & \\
\hline million dollar booty & $\mathrm{L}$ & $\mathrm{R}$ & $\mathrm{D}$ & $\mathrm{R}$ \\
\hline security nightmare & $\mathrm{R}$ & $\mathrm{L}$ & & \\
\hline Olympic park bombing & $\mathrm{L}$ & $\mathrm{R}$ & $\mathrm{D}$ & $\mathrm{R}$ \\
\hline law-enforcement agencies & $\mathrm{L}$ & $\mathrm{R}$ & & \\
\hline Atlanta budget & $\mathrm{L}$ & $\mathrm{R}$ & & \\
\hline team sport & $\mathrm{L}$ & $\mathrm{R}$ & $\mathrm{L}$ & $\mathrm{R}$ \\
\hline home team & $\mathrm{L}$ & $\mathrm{R}$ & & \\
\hline Winter Olympics & & & $\mathrm{L}$ & $\mathrm{R}$ \\
\hline hockey team & & & $\mathrm{R}$ & $\mathrm{L}$ \\
\hline patriot games & & & $\mathrm{L}$ & $\mathrm{R}$ \\
\hline Salt Lake & & & $\mathrm{L}$ & $\mathrm{R}$ \\
\hline
\end{tabular}

(ii) The picture emerging from a detailed analysis of our experimental data is not very optimistic for the distinction of compounds and phrases by means of stress. The data confirm considerable variation and inconsistency in placing stress within $\mathrm{N}+\mathrm{N}$ constructions. There are at least three subjective factors "contributing" to this unfavourable situation and which were paid little or no attention in the previous experimental research, including

a. significant individual differences in isolated pronunciation;

b. significant individual differences in contextual pronunciation;

c. considerable differences between the intuition-based expectations of experts and concrete pronunciation of language users.

(iii) As for compound stress vs. phrasal stress, there is a strong tendency for isolated $\mathrm{N}+\mathrm{N}$ constructions to place the stress on the left-hand constituent. This is mainly true of isolated pronunciation; with contextual realisation, this tendency is much weaker. 
(iv) While both the semantic and structural principles of stress assignment play their important role, our experimental research indicates that the semantic one is more powerful in predicting the position of stress in $\mathrm{N}+\mathrm{N}$ constructions. However, this point needs to be confirmed/rejected by further experimental research and a lot more data. It may be postulated that these two factors plus the analogy factor (if applicable) may have their unequal impact on the position of stress with $\mathrm{N}+\mathrm{N}$ constructions. A question is whether there is any synergic effect of these factors and if yes under what circumstances.

(v) Our research does not confirm a postulate of an interconnection between the stress pattern and the position of an $\mathrm{N}+\mathrm{N}$ construction within the sentence. The variation and differences occur at the beginning, in the middle as well as at the end of sentences.

(vi) Last but not least, we believe that the research has also contributed methodologically to the laboratory research of $\mathrm{N}+\mathrm{N}$ constructions, i.e., in the area which has been long neglected.

\section{Appendix A}

\section{An accidentally selected newspaper text used in the experiment}

There was a moment in the fall, back when BASEBALL was suspended and planes were empty, when the prospect of the 2002 WINTER OLYMPICS was confounding at every turn. We were waging war; who could think of fun and Games? Some SALT LAKE CITY RESIDENTS, sensing a BULL'S EYE painted on their town, wished it would all be canceled; students petitioned that their school be closed for SECURITY REASONS. The athletes, like the rest of us, were disturbed, distracted; a couple had lost relatives in the attacks. NBC was worried that its $\$ 545$ million investment for BROADCAST RIGHTS might be wasted, and started polling to see in anyone planned to watch.

But as the Olympic Torch burned its way from Olympia to Atlanta, then started winding toward SALT LAKE, the ground began to warm. The flame will travel 13,500 miles by DOGSLED and WhEELCHAIR and SNOWSHOE and TENNIS SHOE and TUGBOAT. Rudy Giuliani carried it, exempted from the organizing committee's rule against elected official as TORChBEARERs. Lyz Glick, widow of Jeremy, a hero of Flight 93, carried it, along with 11,498 others, through frigid streets lined with cheering people-and that was just for the torch.

Olympic organizers, more determined than ever to market the meaning, began talking about the Games as a chance for restoring America's hope. There were recollections of the 1980 U.S. HOCKEY TEAM that won its PROXY WAR against the Soviets, who themselves were then at war in Afghanistan. These Games would transcend even politics and patriotism on their way toward therapy. "This is an important event under any circumstance," Utah Governor Mike Leavitt had said a few weeks after the 


\section{PAVOL ŠTEKAUER - JÚLIUS ZIMMERMANN - RENÁTA GREGOVÁ}

attacks, "but fate may have fallen upon this state and city to host an event where the world will come together to heal."

That's a lot to ask, given the history: 2002 had been called the BRIBERY GAMES, for the MILLION-DOLLAR BOOTY dangled before Olympic bigwigs by SALT LAKE OFFICIALS in hopes of its being picked as host. Once the financial scandals passedBRIBERY CHARGES against two of the local organizers were dismissed, although the government is appealing - the SECURITY NIGHTMARE erupted. Ever since the OLYMPIC PARK BOMBING in Atlanta in 1996, LAW-ENFORCEMENT AGENCIES have known they would have to reinvent Salt Lake's security. The ATLANTA BUDGET was more than doubled for SALT LAKE, and after Sept. 11, it increased an additional 25\%, to $\$ 300$ million, for the creation of the Bubble. There will be METAL DETECTORS and spy cameras everywhere, antibiotics and vaccines stockpiled, F-16s overhead and the Secret service on SNOWMOBILES. It's a whole new TEAM SPORT, the FBI and Secret service for once sharing information, patrolling in tandem. HOMELAND SECURITY CHIEF Tom Ridge has called SALT LAKE the safest place in the world; but, he adds, there is no guarantee that the system is fail-safe.

And then there is the HOST-COUNTRY CODE of conduct and the debate over just how red-white-and-blue the Games should be. It's great to cheer the HOME TEAM, but the Olympics is meant to celebrate the international community. "To ask people to love one another is merely a form of childishness," said baron Pierre de Coubertin, founder of the modern Games. "To ask them to respect each other is not utopian, but in order to respect each other they must first know each other." For all the talk of PATRIOT GAMES, the hope is that Americans will be particularly gracious to their global guests, aware that playing host to the Games is not the same as owning them, and conscious, in a whole new way, of being part of a community larger than the U-S-A! U-S-A!

\section{Appendix B}

\section{Thirty-one isolated $\mathbf{N}+\mathbf{N}$ constructions extracted from the original text}

\begin{tabular}{|c|c|c|}
\hline baseball & Winter Olympics & Salt Lake City residents \\
\hline bull's eye & security reasons & broadcast rights \\
\hline Salt Lake & dogsled & wheelchair \\
\hline snowshoe & tennis shoe & tugboat \\
\hline torchbearers & hockey team & proxy war \\
\hline bribery games & million-dollar booty & Salt Lake officials \\
\hline bribery charges & security nightmare & Olympic Park bombing \\
\hline law-enforcement agencies & Atlanta budget & Salt Lake \\
\hline metal detectors & snowmobiles & team sport \\
\hline homeland security chief & host country code & home team \\
\hline
\end{tabular}




\section{References}

Bauer, Laurie 1978. The grammar of nominal compounding with special reference to Danish, English and French. Odense University Press, Odense.

Bauer, Laurie 1983. English word-formation. Cambridge University Press, Cambridge.

Bauer, Laurie 1998. When is a sequence of two nouns a compound in English? In: English Language and Linguistics $2: 65-86$.

Chomsky, Noam - Morris Halle 1968. The sound pattern of English. Harper \& Row, New York.

Dowty, David 1979. Word meaning in Montague Grammar. Reidel, Dordrecht.

Farnetani, Edda - Carol Taylor Torsello - Piero Cosi 1988. English compound versus non-compound noun phrases in discourse: An acoustic and perceptual study. In: Language and Speech $31: 157-80$.

Giegerich, Heinz 2004. Compound or phrase? English noun-plus-noun constructions and the stress criterion. In: English Language and Linguistics 8:1-24.

Jones, Daniel 1969. An outline of English phonetics. Heffer \& Sons, Cambridge.

Kingdon, Roger 1958. The groundwork of English stress. Longman, London.

Kingdon, Roger 1966. The groundwork of English intonation. Longman, London.

Ladd, Robert D. 1984. English compound stress. In: Dafydd Gibbon-Helmut Richter (eds): Intonation, accent and rhythm. Studies in discourse phonology, 253-66. Walter de Gruyter, Berlin \& New York.

Lees, Robert B. 1960. The grammar of English nominalizations. Indiana University Press, Bloomington.

Liberman, Mark - Richard Sproat 1992. The stress and structure of modified noun phrases in English. In: Ivan Sag-Anna Szabolcsi (eds): Lexical matters, 131-81. CSLI Publications, Stanford CA.

Marchand, Hans 1960. The categories and types of present-day English wordformation: A synchronic-diachronic approach. Otto Harrassowitz, Wiesbaden.

Olsen, Susan 2000. Compounding and stress in English: A closer look at the boundary between morphology and syntax. In: Linguistische Berichte 181:55-69.

Pennanen, Esko V. 1980. On the function and behaviour of stress in English noun compounds. In: English Studies $61: 252-63$.

Plag, Ingo 2006. The variability of compound stress in English: Structural, semantic and analogical factors. In: English Language and Linguistics $10: 143-72$.

Roach, Peter 1983. English phonetics and phonology: A practical course. Cambridge University Press, Cambridge.

Sampson, Rodney 1980. Stress in English N + N phrases: A further complicating factor. In: English Studies. A Journal of English Language and Literature $3: 264-70$.

Spencer, Andrew 2003. Does English have productive compounding? Ms. Retrieved June 21, 2004, from http://privatewww.essex.ac.uk/ spena/papers/englishcompounds.pdf.

Zimmer, Karl E. 1971. Some general observations about nominal compounds. In: Stanford University Working Papers on Language Universals 5:1-21. 